\title{
Aspectos Da Violência Obstétrica No Brasil
}

\section{Aspects Of Obstetric Violence In Brazil}

DOI: $10.46919 / \operatorname{archv2n3-006}$

Recebimento dos originais: 01/05/2021

Aceitação para publicação: 30/06/2021

\section{Polyana Magna Lima Dias}

Especialista em Saúde da Mulher.

Hospital Universitário Alcides Carneiro de Campina Grande, PB

R. Carlos Chagas, s/n - São José, Campina Grande - PB, 58400-398

E-mail: polyanamagna@ hotmail.com

\section{Simone Regina Alves de Freitas Barros}

Doutoranda do Programa de Pós-Graduação em Sociedade, Tecnologias e Políticas Públicas do Centro Universitário Tiradentes de Maceió, Alagoas, Brasil

Av. Comendador Gustavo Paiva, 5017 - Cruz das Almas, Maceió - AL, 57038-000

E-mail: simone.barros@ souunit.com.br

\section{Pedro Henrique de Barros Falcão}

Doutor. Professor Adjunto da Universidade Estadual de Pernambuco, Recife, Pernambuco, Brasil Av. Agamenon Magalhães, S/N - Santo Amaro - Recife - PE - 50100-010

E-mail: pedro.falcão@upe.br

\section{RESUMO}

A violência obstétrica é uma situação que acontece com a mulher durante a gravidez, parto e puerpério, construída ao longo do tempo, devendo ser desconstruída pela geração presente e futura. OBJETIVO: Analisar aspectos da violência obstétrica no Brasil, através de pesquisa teórica, bibliográfica e descritiva. CONCLUSÃO: A violência obstétrica precisa ser questionada e quanto mais informação a mulher e sua rede de apoio buscar durante a gestação, mais capacitados estarão para lidarem com essas situações e se sentirem seguros para questionarem os profissionais e tomarem suas decisões assertivas. Por enquanto, não existe lei que defina o que é violência obstétrica no Brasil, porém existem alguns diplomas legais que foram criados para trazer maior conforto à gestante. Justifica-se, portanto, o tema por ser uma problemática relevante do ponto de vista jurídico e social, revestindo-se também de considerável atualidade. Assim, espera-se contribuir para os estudos referentes a este âmbito ora tão questionável.

Palavras-chave: Violência. Brasil. Sociedade.

\begin{abstract}
Obstetric violence is a situation that happens to women during pregnancy, childbirth and the puerperium, built over time, and must be deconstructed by the present and future generations. OBJECTIVE: To analyze aspects of obstetric violence in Brazil, through theoretical, bibliographic and descriptive research. CONCLUSION: Obstetric violence needs to be questioned and the more information the woman and her support network seek during pregnancy, the better they will be able to deal with these situations and feel safe to question the professionals and make their assertive decisions. For the time being, there is no law that defines what obstetric violence is in Brazil, but there are some legal diplomas that were created to bring greater comfort to pregnant women. Therefore, the theme is justified because it is a relevant issue from a
\end{abstract}


legal and social point of view, and is also of considerable relevance. Thus, it is expected to contribute to the studies related to this scope that is now so questionable.

Keywords: Violence. Brazil. Society.

\section{INTRODUÇÃO}

A violência caracteriza-se como um grave fenômeno social que está em franca expansão, em todas as suas formas e, de modo especial, contra a mulher, ao longo da história e nos dias atuais ganhou "caráter endêmico", fazendo-se cotidianamente presente em comunidades e países de todo o mundo, sem discriminação social, racial, etária ou religiosa (Foneite; Feo; Merlo, 2012).

No Brasil, a violência que se encontra ainda silenciada, diante de tantas outras, é a violência obstétrica. Trata-se de uma violência de gênero que foi construída ao longo do tempo, mas que deve ser desconstruída pela geração presente e futura.

Dentro deste contexto, observamos que a violência obstétrica está relacionada aos procedimentos primitivos causados pelos profissionais, aos atos influenciados na comodidade particular e a omissão. Logo, as distintas fases dessa violência podem provocar à gestante: complicações na sua sexualidade, autoestima, visão do próprio corpo, entre outras. Isso tudo, pode desencadear a depressão pós-parto e crises de ansiedade que podem resultar em transtornos psicológicos, geralmente a mulher impute a culpa ao filho que está nascendo.

Quando a mulher passa por uma violência obstétrica, ela está muitas vezes tão concentrada no momento da sua gestação, parto e suas ansiedades peculiares que não percebe a violência sendo praticada. Às vezes, no cenário do parto, qualquer outra pessoa consegue ver e perceber a violência obstétrica, mas a própria mulher não. Com o conhecimento do que envolve essa prática e estando bem informada sobre seus direitos, essa mulher perceberá quando está sendo vítima e exigirá a atenção que lhe é necessária.

O tema do presente estudo apresenta a questão da violência obstétrica na sociedade brasileira, especialmente em relação aos termos e definições da violência obstétrica, como também a dignidade da pessoa humana, buscando responder o seguinte questionamento: $\mathrm{O}$ que fazer juridicamente para respeitar a dignidade da mulher durante a gestação, parto e puerpério?

Desse modo, este estudo visa analisar criticamente se as hipóteses disponibilizadas pelo ordenamento jurídico brasileiro são propiciadoras de um adequado enquadramento aos causadores da violência obstétrica.

Portanto, a abordagem do estudo é meramente qualitativa, realizada através de pesquisa teórica, bibliográfica e descritiva envolvendo material nacional e internacional e do método dedutivo, buscando a subjetividade por meio da interpretação e compreensão. 
Em suma, tenta-se demonstrar neste trabalho que o tema é motivo gerador de inúmeras controvérsias, tanto pela doutrina quanto pela jurisprudência pátria, mostrando que os entendimentos apregoados em livros e ensaios jurídicos são transportados para sentenças e acórdãos, tendo a força de solucionar um caso concreto posto a julgamento.

\section{DESENVOLVIMENTO}

\subsection{VIOLÊNCIA OBSTÉTRICA}

Consoante pesquisa literária, a violência obstétrica refere-se aos diversos tipos de agressão que as mulheres podem sofrer no pré-natal, no parto, pós-parto ou em situações de abortamento. Normalmente, são violências perpetradas por profissionais de saúde que ao atender esta mulher que já está bem debilitada, que está com medo do parto, que tem medo da gravidez, tende a ceder para todas as pressões que lhe são impostas durante esse período.

Ainda neste sentido, a violência obstétrica é um ato deliberado de agressão à saúde da mulher. Sem dúvida alguma, é um problema de saúde pública, reconhecido desse modo pela Organização Mundial de Saúde, e que deve ser tratado com rigor. Pois, ela desencadeia outros tipos de doenças e disfunções no corpo da vítima, sempre precisando de apoio psicológico posteriormente.

A gestação e o parto são momentos muito íntimos e aguardados pela mulher gestante. Porém, um processo que deveria ser natural acaba muitas vezes se tornando um momento de agressão e de trauma, por conta dos processos de intervenção e os maus tratos praticados contra essas mulheres.

Além disso, segundo Leat e colaboradores (2014), essas intervenções costumam acontecer após uma série de violências menores: litotomia, tratamento degradante, uso rotineiro de ocitocina, episiotomia, manobra de Kristeller, o desrespeito ao direito de acompanhamento, cirurgia cesariana sem indicação e etc. Tais práticas podem gerar graves sequelas e representam grave violação dos direitos sexuais e reprodutivos das mulheres.

Segundo a pesquisa "Mulheres brasileiras e gênero nos espaços público e privado", da Fundação Perseu Abramo, realizada no ano de 2010, 25\% das mulheres brasileiras relatou ter sofrido violência obstétrica. Isso se torna cada vez mais preocupante e grave problema de saúde no Brasil (Fundação Perseu Abramo, 2010).

$\mathrm{Na}$ atualidade, temos na equipe hospitalar, o acompanhamento do profissional médico durante trabalho de parto, sabe-se que nem sempre foi assim. Na verdade, verificamos que o médico como membro da equipe multiprofissional durante o trabalho de parto foi uma construção que se deu ao longo dos últimos séculos, porque antes as mulheres quando estavam grávidas procuravam parteiras que normalmente eram 
mulheres e que tinham conhecimentos de ordem prática, porque já vinham fazendo isso ao longo de suas vidas e esse momento fisiológico acabava sendo conduzido por essas mulheres.

De acordo com Vieira (2002), a classe médica começou a ter mais interesse nesse processo e foi criada a especialidade de obstetrícia, sendo importante destacar que isso foi dentro de um processo bastante intervencionista. Essa classe médica junto com a Igreja e o Estado passaram a fazer campanha de afastamento das parteiras, especialmente, por conta do controle reprodutivo no qual a Igreja Católica entendia que as parteiras estavam associadas ao processo de abortamento e outras práticas tidas como moralmente equivocadas.

É importante destacar que as parteiras foram bastante perseguidas durante o processo de inquisição e muitas delas foram mortas nas fogueiras como bruxas. Isso aconteceu por causa desses conhecimentos que elas exerciam e que era uma forma tida como influência maléfica somente porque estava dentro da seara do feminismo e esse processo se inseriu dentro do movimento chamado positivismo. Esse processo buscou dar maior importância para o racionalismo e o conhecimento científico, ocorrendo um apagamento das posturas dessas parteiras que tinham conhecimento prático muito importante e todo o controle reprodutivo foi transferido para a classe médica.

Pasche, e colaboradores (2010), apontam que a partir desse processo de medicalização, é muito comum que haja uma série de intervenções que sendo notificadas, supostamente, a partir da ciência de que geram danos e uma série de corte da autonomia da mulher, reduzindo a capacidade dessa mulher de direcionar o trabalho de parto e o bem-estar do bebê que está para nascer. Assim, todas as decisões são colocadas nas mãos do médico que não tem, muitas vezes, relação especifica com aquela pessoa e com aquela realidade.

Para Mendonça e colaboradores (2021), diz que é importante o acompanhamento da família durante todas as fases do período gravídico-puerperal, uma vez que a violência à mulher pode ser evitada durante esse ciclo.

Deste modo, a violência obstétrica é toda ação e omissão que prejudique a mulher dentro do seu processo reprodutivo, e isso pode ocorrer de várias formas. Vejamos alguns exemplos mais recorrentes:

- Violência verbal: aquela em que é utilizada palavras que ofendem moralmente a mulher no ciclo gravídico-puerperal. Exemplo: Quando a gestante está sofrendo na hora do parto, tendo dor e alguém a manda ficar calada porque não estava chorando quando fez;

- Violência sexual: aquela que afeta toda a dignidade da mulher através de procedimentos. Exemplo: Quando é feito uma episiotomia (corte na lateral da vagina da mulher com o intuito de evitar que haja uma fissura na hora que o bebê é expulso, ocasionando maior lesão ao períneo da mulher). 
No Brasil, existem procedimentos físicos que costumam ser feitos como se fossem protocolos, sendo que só poderiam ser feitos em casos extremos para evitar danos maiores a e evitar danos irreversíveis. Porém, isso ainda é utópico perante nossa realidade (Diniz \& Chacham, 2006; Leal et al., 2014; Pasche et al., 2010; Tornquist, 2002).

É importante destacar um procedimento físico, chamado de "ponto do marido" que costuma ser feito aqui no Brasil, e que a gênese do nome já sugere o quão errado é esse procedimento. Basicamente, é um ponto em que é dado sem que as mulheres tenham conhecimento e nem que elas tenham dado consentimento para esse procedimento que consiste em supostamente apertar a vagina dela que teria ficado alargada após o parto. Sendo que, se as mulheres tomarem os cuidados necessários durante a gestação é um processo que voltará ao normal e a mulher terá sua elasticidade que ela tinha antes. Só que o ponto do marido pode gerar efeitos maiores na vida dessa mulher. As mulheres testemunham dor depois de passaram por esse procedimento, muitas dificuldades em ter relações sexuais. Até o nome evidencia que não é a saúde da mulher que está em jogo, mas o prazer masculino do seu companheiro que não quer transar com uma mulher, popularmente falando, "arregaçada" e isso é um absurdo extremamente machista.

Além disso, há uma série de tratamentos que são concedidos a mulher que está em trabalho de parto que são muito prejudiciais: a recusa de dar analgesia quando solicitada; a recusa de dar alimentos sólidos quando a mulher está em trabalho de parto (não há evidência científica que isso seja prejudicial e está conduzindo a mulher a um processo de tortura por várias horas sem dar a ela o que é necessário); deixá-la sem direito ao acompanhante, sendo que a lei determina que toda mulher em trabalho de parto tem direito a um acompanhante justamente para evitar que as distorções aconteçam porque com uma testemunha é mais difícil que ela seja submetida a esse tipo de tratamento. Vale destacar que alterar ou omitir informações sobre o trabalho de parto dessa mulher também é uma forma de violência obstétrica.

Ato muito recorrente é não permitir que a mulher fique com seu filho logo após o nascimento. É muito comum à equipe médica retirar o bebê do local do parto, colocar no berçário em outro local e não permitir que a mãe nesses primeiros momentos tenha contato especificamente pele a pele com seu filho. Há uma série de evidências que explicam inúmeros benefícios para saúde do bebê e da mãe que tenha efetuado esse contato no primeiro momento, porque há, inclusive, troca de fatores biológicos que fortalecem a imunidade do bebê e que são muito benéficos para construção do vínculo entre a mãe e o filho e que precisa ser realmente efetivados nesse momento.

Outra forma muito comum de violência obstétrica é a chamada manobra de Kristeller. Essa manobra, basicamente, ocorre quando a mulher está em trabalho de parto e, muitas vezes, as enfermeiras ou médicos empurram a barriga da gestante para que o bebê saia a partir desse esforço externo. Sendo que não há nenhuma evidência científica que isso colabore para o trabalho de parto efetivo, ao contrário, essa é 
uma violência evidente para com a mulher que está parindo e que pode inclusive prejudicar e gerar uma necessidade de episiotomia que é um absurdo ou rompimento do útero.

Portanto, muitas vezes essas intervenções médicas desnecessárias são uma cascata que geram cesárias de emergência obrigatória. A OMS entende que apenas de $10 \%$ a $15 \%$ das cesáreas seriam de fato necessárias e que contribuem para a saúde da mãe e do bebê. Assim, o Brasil ocupa o segundo lugar no ranking realizado pela OMS dos países que mais efetuam cesáreas eletivas e isso é bastante preocupante para a saúde pública brasileira.

\subsubsection{Definições e termos acerca da denominação "violência obstétrica"}

Apesar de ser tratada com a expressão violência obstétrica, existem algumas polêmicas quanto a essa denominação. Pois, ela tem uma dificuldade em ser aceita porque a violência obstétrica já consagrada na literatura médica é um nome que ele oferece um conceito equivocado do que venha a ser essa violência. Imagina-se, se for perguntado a um leigo, que ela vai responder que a violência obstétrica é aquela praticada por um obstetra. Claro que pode ser por um obstetra, mas a violência obstétrica é algo muito maior do que isso, pois, pode ser causada por qualquer profissional da saúde ou familiar.

A Federação Brasileira das Associações de Ginecologia e Obstetrícia (FEBRASGO) elucida grande luta pela denominação "violência contra a mulher". Em maio de 2019, o Ministério da Saúde fez uma recomendação ( $n^{\circ} 5$ de 2019) de que não usaria mais o termo violência obstétrica, e que o novo termo deveria ser atualizado aos poucos, seguindo orientações do Conselho Federal de Medicina (nota à imprensa expedida em 09 de maio de 2019) e de outras entidades médicas.

Esse termo utilizado pela Organização Mundial de Saúde determina alguns procedimentos e condutas que contrariam a vontade da gestante e terceiros, considerados abusivos e caracterizam-se como violência obstétrica.

O termo violência nos traz a ideia de que é tudo aquilo que foge do que deveria ser normal, do que deveria ser uma conduta adequada. A conduta abusiva é uma conduta violenta e o Ministério da Saúde afirma que o termo violência obstétrica tem conotação inadequada, não agrega valor e prejudica a busca do cuidado humanizado.

Recentemente, o Ministério da Saúde emitiu um despacho informando que quer abolir a expressão violência obstétrica das novas portarias e essa decisão causou uma grande preocupação, inclusive, do Ministério Público Federal, no qual este emitiu uma recomendação (29/2019) para que essa expressão continue a ser utilizada nas portarias, porque não se pode colocar "sujeira por debaixo dos panos". Pois, a proibição do uso da terminologia em nada ajudará na construção de políticas para coibi-la. 
Embora o termo violência obstétrica possa nos sugerir que somente médicos possam realizar esses atos violentos, isso é errôneo, porque qualquer profissional ou prestador de serviço na saúde pode cometer a violência contra a mulher no ciclo gravídico-puerperal. Normalmente, associamos a violência obstétrica realizada pelos profissionais de saúde que são os responsáveis pelo atendimento mulher no pré-parto, no parto e no pós-parto, mas a violência obstétrica também pode ser cometida por familiares, mas a depender do contexto, a violência realizada pelos familiares é uma forma de violência doméstica, valendo-se da lei Maria da Penha.

\subsubsection{Humanização ao direito de nascer}

Segundo Deslandes (2004), humanizar diz respeito à prestação de uma assistência que tenha como prioridade a qualidade do cuidado garantindo o respeito quanto aos direitos do paciente, sua individualidade e cultura, bem como a valorização do profissional que presta a assistência, estabelecendo um ambiente concreto nas instituições de saúde, que regularize o lado humano das pessoas envolvidas no processo de cuidar (Pessini, 2004).

O conceito de atenção humanizada durante a parturição engloba conhecimentos, práticas e atitudes que têm em vista garantir o parto e nascimento saudáveis, levando em consideração a prevenção da morbimortalidade materna e perinatal (Brasil, 2001). Portanto, exprime a necessidade de alterações no entendimento do parto, como experiência humana e, para aquele que presta o atendimento, uma transformação em como agir no momento oportuno diante do sofrimento do outro (Diniz, 2001)

O profissional que deveria passar segurança, confiança para a parturiente, com sua conduta aguçou seus medos e anseios. Refletir sobre esse fato faz reiterar a importância do preparo do profissional que presta a assistência à gestante e ou parturiente. É de fundamental importância que os profissionais de saúde, indiferentemente do cargo que ocupam, tenham habilidade, competência técnica e controle emocional para prestar a assistência (Milbrath et al., 2010).

Em 2001, o Ministério da Saúde editou a portaria $n^{\circ} 5691$, tratando do acesso e garantia amplos à saúde para gestantes e recém-nascidos. Buscando aprimorar o tratamento da saúde da mulher, desta vez com atenção ao período gestacional, o diploma legal instituiu medidas como a implantação das redes de assistência à gestação de alto risco, o incremento do custeio e a realização de investimentos nas unidades hospitalares integrantes destas redes, além de prosseguir à política, já iniciada nos anos 80 .

Art. $1^{\circ}$ Instituir o Programa de Humanização no Pré-natal e Nascimento, no âmbito do Sistema Único de Saúde.

Art. $2^{\circ}$ Estabelecer os seguintes princípios e diretrizes para a estruturação do Programa de Humanização no Pré-natal e Nascimento: a - toda gestante tem direito ao acesso a atendimento digno e de qualidade no decorrer da gestação, parto e puerpério;

b - toda gestante tem direito ao acompanhamento pré-natal adequado de acordo com os princípios gerais e condições estabelecidas no Anexo I desta Portaria; 
c- toda gestante tem direito de saber e ter assegurado o acesso à maternidade em que será atendida no momento do parto;

$\mathrm{d}$ - toda gestante tem direito à assistência ao parto e ao puerpério e que esta seja realizada de forma humanizada e segura, de acordo com os princípios gerais e condições estabelecidas no Anexo II desta Portaria;

e - todo recém-nascido tem direito à assistência neonatal de forma humanizada e segura;

f - as autoridades sanitárias dos âmbitos federal, estadual e municipal são responsáveis pela garantia dos direitos enunciados nas alíneas acima.

Desde 2001, portanto, o Brasil reconhece a obrigação das entidades estatais em garantir tanto à gestante quanto ao recém-nascido um atendimento humanizado, como premissa de uma vida digna. Desde então, diversos outros diplomas tratando destes direitos foram editados, como a lei 11.108/09 que garante a presença de um acompanhante, de escolha da grávida, durante o período de parto e pós-parto.

Pela portaria 1.459/11 do Ministério da Saúde, foi criada a Rede Cegonha, que, segundo o art. $1^{\circ}$ desta resolução: consiste numa rede de cuidados que visa assegurar à mulher o direito ao planejamento reprodutivo e à atenção humanizada à gravidez, ao parto e ao puerpério, bem como à criança o direito ao nascimento seguro e ao crescimento e ao desenvolvimento saudáveis, denominada Rede Cegonha. O programa federal busca instituir um atendimento diferenciado à gestante, desde o momento da descoberta da gravide até o parto, disponibilizando profissionais especializados para o atendimento e também indicando à mulher qual será o hospital de referência para o nascimento do bebê, o que lhe dá mais segurança no momento do trabalho de parto.

Segundo Sarlet (2001), a dignidade da pessoa humana é atingida no momento em que determinada pessoa for descaracterizada ou desconsiderada enquanto sujeito de direitos. Nesse sentido, Beck (apud Mattos et al, 2015) enfatiza que a consideração do ser humano como um fim em si mesmo, dotado de dignidade, só tem sentido se este for concedido como capaz de autêntica moralidade, e então livre na sua vontade, como pessoa autônoma. Sob essa perspectiva, a dignidade da pessoa humana como princípio jurídico "vai designar não apenas o "ser da pessoa", mas a "humanidade da pessoa"” (Costa, 2000).

Consoante Barroso (2010), a dignidade da pessoa humana abarca três conteúdos essenciais: valor intrínseco, autonomia e valor social da pessoa humana. O valor intrínseco é a posição especial no mundo que distingue o ser humano dos outros seres vivos e das coisas. No plano jurídico, o valor intrínseco da pessoa humana impõe a inviolabilidade da sua dignidade, sendo inerente a uma série de direitos fundamentais: o direito à vida, direito à igualdade, direito à integridade física, além da integridade moral ou psíquica - direitos que têm sido fortemente violados se observados sob a perspectiva da violência obstétrica.

O modelo de atenção tecnocrático, intervencionista e que desconsidera as evidências científicas e os aspectos subjetivos concernentes à experiência do parto e nascimento, é verificado tanto no âmbito da atenção privada como também na rede pública. (D’orsi et al., 2014) 
Segundo Fassin e colaborador (2011), trauma tem sido visto como algo que é e está, sempre existindo diante de situações de violência ou acidentes; ele seria uma verdade compartilhada. No entanto, eles propõem refletir sobre essa noção de modo historicizado, pensando a sua construção a partir do desenvolvimento dos domínios da psiquiatria, da psicologia e da psicanálise, entrelaçando essa genealogia com o seu duplo, que seria o reconhecimento, pela sociedade, de que determinados eventos teriam por consequência inevitável traumatizar os sujeitos neles presentes. Para eles, o fato das pessoas reivindicarem o status de vítima e, portanto, de se colocarem como traumatizadas por alguma situação e por isso acharem merecer algum tipo de reparação pelos danos sofridos seria resultado de uma transformação moral daquilo que constitui a humanidade. Tratar-se-ia daquilo que eles denominam "políticas do trauma": uma articulação entre um evento que é coletivo e que dá sustentação ao trauma e a experiência individual vivida nesse evento coletivo, que servirá de testemunha ao seu aspecto traumático.

É importante ressaltar que no Brasil, ao contrário de países como Argentina (Lei Nacional n 25.929) e Venezuela (Guerra, 2012), ainda não consta na legislação uma lei específica que caracterize a violência obstétrica. Conforme definição da Defensoria Pública do Estado de São Paulo (DPESP, 2013), violência obstétrica caracteriza-se pela apropriação do corpo e dos processos reprodutivos das mulheres pelos profissionais de saúde, através do tratamento desumanizado, abuso da medicalização e patologização dos processos naturais, causando a perda da autonomia e capacidade de decidir livremente sobre seus corpos e sexualidade, impactando negativamente na qualidade de vida das mulheres (DPESP, 2013).

\subsubsection{Violência obstétrica à luz do ordenamento jurídico brasileiro}

No cenário brasileiro violência obstétrica não é crime, como o caso de países como a “Argentina Leis Nacionais n 25.929 e 26.485 e Venezuela Ley Orgánica sobre el Derecho de las Mujeresa uma Vida Libre de Violência de 19/03/2007", conforme explanou-se no dossiê "Parirás com dor".

Ao pesquisarmos na jurisprudência brasileira o termo "violência obstétrica" e não encontrarmos processos com essa denominação, mas somente situações de violência obstétrica sobre o termo erro médico tem um problema. Se for um erro, nós estamos lidando com um tipo de licitude, mas sendo uma violência, estamos lidando com uma responsabilidade penal. Então, a violência obstétrica precisa-se ser preservada enquanto termo, mas ela ainda é confundida na jurisprudência como erro médico.

Utilizando a denominação erro médico, nos deparamos que há entre uso de ocitocina, uso de manobra de Kristeller, episiotomia e outras inúmeras séries de violências que estão camufladas sobre o termo erro. Isso implica que a mulher só pode efetivamente ajuizar ações civis. Porém, se estamos diante de uma violência, é necessário ir à busca da responsabilidade penal desses profissionais em relação à violência obstétrica. 
Decisões do Ministério da Saúde acabam gerando conflitos entre o que determina o Código Civil, a Constituição Federal, determinadas resoluções do Conselho Federal de Medicina e do próprio Ministério da Saúde. Há em tramitação no Congresso Nacional um projeto de lei sobre o assunto violência obstétrica e a ideia é que criminalize esses atos., pois, somente a União pode determinar uma lei penal.

Em Santa Catarina existe a lei 19097/2017 visa implementar medidas de informação e proteção à gestante e parturiente contra a violência obstétrica no Estado, uma política pública para redução da violência obstétrica, mas ela não pode criminalizar essas ações. A ideia é que seja diminuída essa violência, sendo encaixada como erro médico ou, então, na busca pela reparação dos danos materiais e morais.

Mesmo não havendo uma lei específica, muitos casos de violência obstétrica chegam ao Supremo Tribunal de Justiça. Recentemente, os Ministros da Terceira Turma confirmaram duas decisões em que os médicos e hospitais foram condenados por falhas na hora do parto. O primeiro caso foi por causa de uma cesariana tardia que ocasionou a paralisia e atrofia cerebral no bebê. Já o segundo, por indução do parto antes da bolsa romper e falta de monitoramento da criança pela equipe médica na troca do plantão, gerando sequelas neurológicas irreversíveis na criança. Nos dois casos, a Relatora Ministra Nancy Andrighi destacou que os hospitais devem ser responsabilizados porque foi comprovada a culpa dos médicos, integrantes dos quadros e que a pretensão das pacientes não seriam para responsabilização exclusivamente dos médicos, mas para qual o defeito da prestação no serviço hospitalar.

Desta forma, o Conselho Federal de Medicina não tem o poder de modificar o reinterpretar normas que estão no Código Civil e na Constituição Federal. A gestante deve ser orientada e deixar claro para seus familiares e acompanhares de que sua opinião será preservada com relação ao tratamento adequado e momento do parto.

O que se espera é o respeito à mulher, a mãe, a gestação, a Constituição Federal, as normas expostas no Código Civil a partir do artigo 11. Não podemos permitir abusos nas resoluções do Conselho Federal de Medicina e do Ministério da Saúde. Surgindo um diferente objeto a ser tutelado, o cerne da problemática é que necessitamos de políticas públicas de reconhecimento de atos violentos no momento do parto, e desta forma além de existir assistência como o pré-natal exista também orientação à gestante até o momento do puerpério, garantindo a possibilidade de denunciar e proteger-se.

Em que pese o posicionamento jurisprudencial, a falta de uma lei específica, assim como punições para aqueles que praticam a violência obstétrica, geram uma grande insegurança para a mulher que já se encontra em um estado de grande vulnerabilidade. O médico sempre irá afirmar que está apenas fazendo seu trabalho e, na maioria das vezes, contará com o apoio do hospital. Cabe ao Direito então estar ao lado da parturiente. Garantindo que ao ter seus direitos ela não precisará se calar por medo 


\section{CONSIDERAÇÕES FINAIS}

A violência obstétrica pode acontecer com qualquer mulher durante o ciclo gravídico puerperal. Negras, indígenas, emigrantes, costumam sofrer mais violência obstétrica porque na sociedade brasileira esse grupo de pessoas sofre mais discriminação, havendo uma interseccionalidade.

Revela-se de grande importância que o Legislativo Federal discipline a temática, até para que se possam definir sanções específicas à violência obstétrica, o que não pode ser feito em sede de leis estaduais e municipais.

Diante de todo o exposto, o presente artigo revelou que, na conjuntura da violência obstétrica, serão necessárias adequações no serviço de saúde. Para que isso aconteça, mudanças no processo de formação dos profissionais de saúde. Dentre elas, a efetivação do olhar humanizado desde a formação até as práticas desses profissionais. Utilizar a internet como ferramenta para promover a conscientização, discussão e quebra da invisibilidade da violência obstétrica, também é estratégico, em função dos benefícios que a participação em ações via internet podem trazer às mulheres que a vivenciam. Também é necessário que as vítimas procurem seus direitos: fazendo Boletim de Ocorrência, procurando o Ministério Público (órgão fiscalizador), ingressando com Ação Judicial, dentre outros meios de fazer valer os seus direitos, mas nunca vindo a calar-se. 


\section{REFERÊNCIAS}

Barroso, L. R.. (2010). A Dignidade da Pessoa Humana no Direito Constitucional Contemporâneo: Natureza Jurídica, Conteúdos Mínimos e Critérios de Aplicação. Versão provisória para debate público. Mimeografado. [Acesso em: 18 de setembro de 2020]. Disponível em: http://www.luisrobertobarroso.com.br/wp-content/uploads/ 2010/12/Dignidade_textobase_11dez2010.pdf.

Brasil. Ministério da Saúde. Secretaria de Políticas de Saúde. Área Técnica de Saúde da Mulher. Parto, aborto e puerpério: assistência humanizada à mulher. Ministério da Saúde, Secretaria de Políticas de Saúde, Área Técnica da Mulher. Brasília, Ministério da Saúde, 2001.

Costa, J. M. Bioética e dignidade da pessoa humana: rumo à construção do Biodireito. Revista da Faculdade de Direito da UFRGS, 2001; v. 18.

Defensoria Pública do Estado de São Paulo. Violência Obstétrica: você sabe o que é? Núcleo especializado de promoção e defesa dos direitos da mulher e Associação Artemis. Escola da Defensoria Pública do Estado. São Paulo. 2013. Disponível em: . Acesso em: 20 de setembro de 2020.

Deslandes, F. S. Análise do discurso oficial sobre humanização da assistência hospitalar. Ciência e Saúde Coletiva. 2004; v. 9(1):7-14.

Diniz, C. S. G. (2001) Entre a técnica e os direitos humanos: possibilidades e limites da humanização da assistência ao parto. [Tese] (doutorado). Faculdade de Medicina/USP. São Paulo.

Diniz, S. G. \& Chacham, A. S. (2006). O “corte por cima” e o “corte por baixo”: o abuso de cesáreas e episiotomias em São Paulo. Questões de saúde reprodutiva, 1(1), 80-91.

D'orsi, E. et al. Social inequalities and women's satisfaction with childbirth care in Brazil: a national hospital-based survey. Cad. Saúde Pública, volume 30, supl. 1, p. S154-S168. 2014. Rio de Janeiro. [Acesso em: 30 de Setembro de 2020]. Disponível em: https://doi.org/10.1590/0102-311X00087813.

Rede Parto do Princípio. Mulheres em Rede pela Maternidade Ativa. Dossiê da Violência Obstétrica "Parirás com dor". Dossiê elaborado pela Rede Parto do Princípio para a CPMI da Violência Contra as Mulheres, 2012, p. 28-29. [Acesso em: 30 de setembro de 2020]. Disponível em: http://partodoprincipio.blogpot.com.br/2013/06

/cpmi-sobreviolencia-contr-mulher.html.

Faneite, J., Feo. A, Merlo, J.T. Grado de conocimiento de violencia obstétrica por elpersonal de salud. RevObstetGinecol Venez. v.72,n.1. 2012. [Acesso em: 30 de setembro de 2020]. Disponível em: http://www.scielo.org.ve/scielo.php?pid=S0048-77322012000100002\&script=sci_arttext.

Fundação Perseu Abramo. Pesquisa Mulheres Brasileiras e Gênero nos Espaços Público e Privado. São Paulo: Fundação Perseu Abramo, 2010.

Guerra, G. B. Violencia obstétrica. Revista de la Facultad de Medicina, 31(1), 5-6. 2012.

Leal, M. C., Pereira, A. P., Domingues, R. M., Theme, M. M., Dias, M. A., Nakamura-Pereira, M et al. Intervenções obstétricas durante o trabalho de parto e parto em mulheres brasileiras de risco habitual. Cadernos de Saúde Pública, 30(Supl. 1), S17-S32. 2014. [Acesso em: 30 de outubro de 2020]. Disponível em: http://dx.doi.org/10.1590/0102-311X00151513. 
Mattos, D.; Ramos, E.; Veloso, R. Entre a autonomia da vontade kantiana e o princípio da autonomia de Beauchamp e Childress: uma discussão acerca da autonomia e da dignidade humana na Bioética e no Direito. Perspectiva Filosófica, 2015; Vol. 42, nº 1. ISSN: 23579986.

DE MENDONÇA, R. S. .; VERA, I. .; LOPES, R. S. .; DE ALCÂNTARA, G. V. V. .; DE SOUZA, L. M. M. . Avaliação das relações familiares durante a gravidez: quais instrumentos são utilizados?. Archives of Health, v. 2, n. 3, p. 209-224, 14 May 2021.

Milbrath, V. M. et al. Vivências maternas sobre a assistência recebida no processo de parturição. Esc. Anna Nery, 2010; 14(2):462-467.

Pasche, D. F., Vilela, M. E. A., \& Martins, C. P. Humanização da atenção ao parto e nascimento no Brasil: pressuposto para uma nova ética na gestão e no cuidado. Revista Tempus Actas Saúde Coletiva, 2010; 4(4):105-117. [Acesso em: 30 de outubro de 2020]. Disponível em: http://dx.doi.org/10.18569/tempus.v4i4.838.

Pessini, L. Humanização da dor e do sofrimento humanos na área da saúde. In: Humanização e cuidados paliativos. Loyola. 2004. p. 12-30. São Paulo.

Sarlet, I. W. Dignidade da pessoa humana e direitos fundamentais na Constituição Federal de 1988. Porto Alegre: Livraria do Advogado. 2001.

Tornquist, C. S. Armadilhas da nova era: natureza e maternidade no ideário da humanização do parto. Revista Estudos Feministas, 2002; 10(2):483-492. [Acesso em: 01 de novembro de 2020]. Disponível em: http://dx.doi.org/10.1590/S0104-026X2002000200016.

VIEIRA, E. M. A medicalização do corpo feminino. Rio de Janeiro: Editora Fiocruz. 2002. 